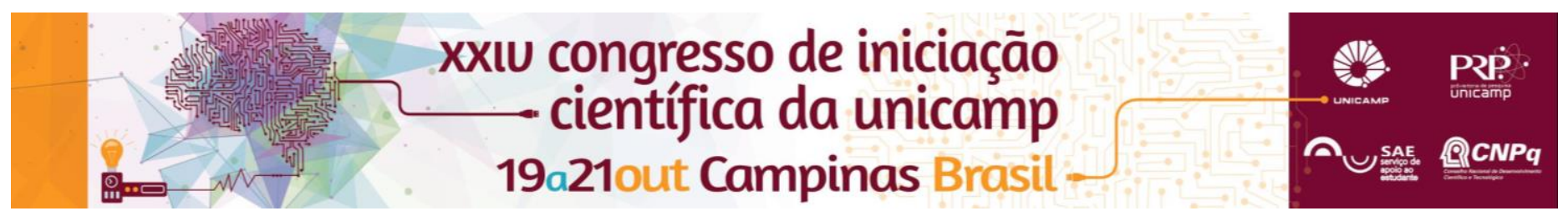

\title{
Software Graphical Interface as a part of a Spoofing System to Take Over Criminal Drones
}

\section{Felipe C. Frazatto*, Mauricio M. Donatti, Leandro T. Manera}

\begin{abstract}
Drones have been used by criminals to smuggle cell phones and drugs into prisons. They also may cause accidents in airports and other heavy flight traffic zones, so it is clear that is interesting to take control of drones in some specific situations. This work is part of a project intended to develop a system (hardware and software) to take control of the lawbreaking drones.
\end{abstract}

\section{Key words:}

RF Spoofing Attack; Drones; Homeland Security.

\section{Introduction}

Nowadays we are experiencing a rapid growth in the drone market and, as consequence, in drone related utilities, ranging from simple flight to military recognition missions. However, some users are taking advantage of this new technology to break the law and smuggle items and drugs into prisons. Criminals used Drones to smuggle drugs and contraband into prisons in New York on Sept. 2015 [1]. São Paulo's police captures Drone taking 18 cell phones to a prison on Aug. 2014 [2] and CCTV shows drone delivering stash of drugs to prison cell window. London, UK on May 2016 [3]

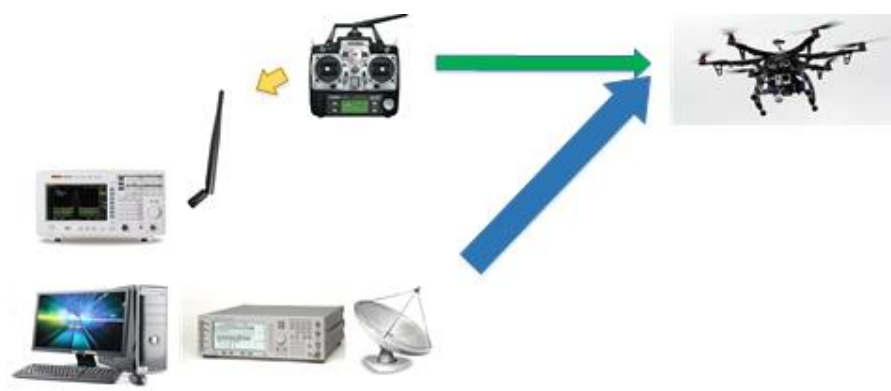

Image 1. System Diagram

To prevent these actions, it is interesting to develop a system that highjacks these drones and take control of them by emulating a similar signal as the drones' controller. Such method is called spoofing [4] as presented in Image 1.

Our system is an incremental innovation from cell phones and Wi-Fi blockers already installed in prisons by Neger Telecom [5]. The research project presented in this work outlines the graphical interface development, programmed using $\mathrm{C \#}$ language.

\section{Results and Discussion}

We have used a beaglebone board, running our spoofing program and a USB connection with an UART (CP2102) to communicate with the graphic user interface.

The GUI, as shown in image 2, developed using de

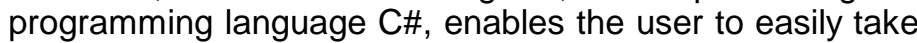
control of the drone and the system itself automatically sending standardized messages to the hardware that in turn sends the simulated signal to the drone.

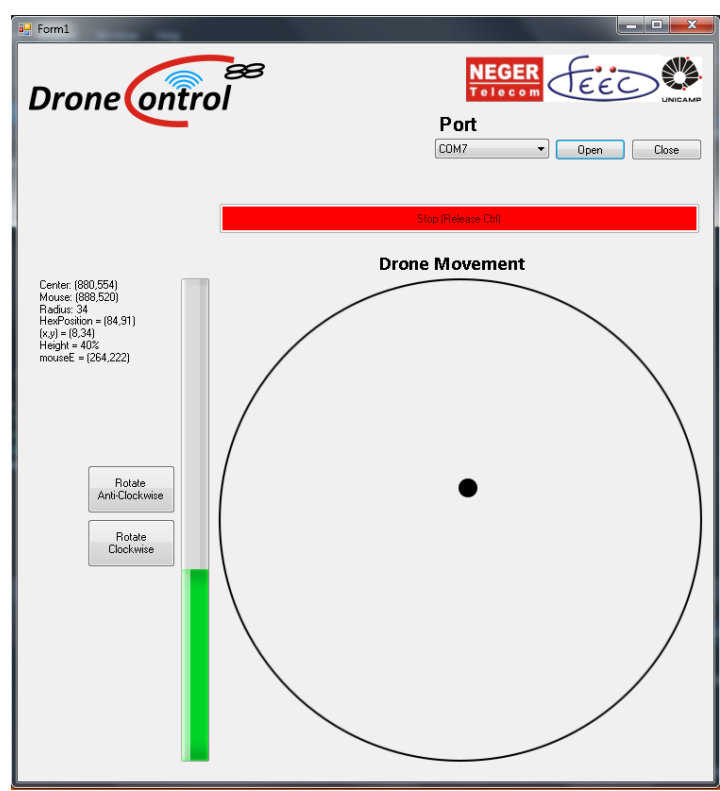

Image 2. Developed Interface (C\#)

\section{Conclusions}

We were able to develop a user friendly interface that enables any user to take control over the drone, enabling the control of all drone flight parameters: Yaw, pitch, throttle and roll.

Further hardware improvements are under development to increase drone models that can be spoofed.

\section{Acknowledgement}

This work was supported by a partnership between Neger Telecom (CNPq RHAE project) and School of Electrical and Computer Engineering (FEEC) at the University of Campinas (UNICAMP).

${ }^{1}$ http://www.slate.com/blogs/future_tense/2016/01/20/criminals_using_drones _to_smuggle_drugs_and_contraband_into_prison.html

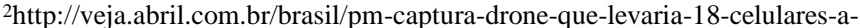
presidio/

${ }^{3}$ http://metro.co.uk/2016/05/17/cctv-shows-drone-delivering-stash-of-drugs-toprison-cell-window-5888281/

${ }^{4}$ KERNS, Andrew J.; SHEPARD, Daniel P. "Unmanned Aircraft and Capture and Control via GPS Spoofing". The University of Texas at Austin.

${ }^{5} \mathrm{http}: / /$ www.neger.com.br/produtos/bloqueador-celular 